\title{
DEVELOPING A SYSTEMATIC APPROACH TO EVALUATE AND PREDICT BUILDING SERVICE LIFE
}

\author{
Chien-Jung CHEN ${ }^{\mathrm{a}}$, Yi-Kai JUAN ${ }^{\mathrm{b}}$, Yin-Hao HSU ${ }^{\mathrm{b}}$ \\ ${ }^{a}$ Architecture and Building Research Institute, Ministry of the Interior, \\ 13F. No. 200, Sec. 3, Beisin Rd., Sindian District, New Taipei City, Taiwan \\ ${ }^{b}$ Department of Architecture, National Taiwan University of Science and Technology, \\ No. 43 Sec. 4, Keelung Road, Taipei, Taiwan
}

Received 15 Feb 2017; accepted 09 May 2017

\begin{abstract}
Analyzing the reasonable service life of buildings is a critical step to evaluate the decision for building utilization, reuse, or disposal. If buildings manifest service value, sustainable refurbishment and reuse methods can be employed to extend their service life. Previous studies on building service life largely focused on physical obsolescence. Few studies have analyzed other aspects. The objective of the present study was to propose a systematic approach to evaluate and predict the reasonable service life of buildings. First, the Fuzzy-Delphi Method (FDM) and analytical hierarchy process (AHP) were adopted to determine the final evaluation criteria and weights. Second, a mathematical model for predicting building service life was developed by combining the evaluation criteria, six obsolescence factors, and diagnostic scores. Finally, the model was applied to four case studies. The results produced by the model were consistent with those determined by an expert panel, verifying its effectiveness as a tool for decision making for formulating favorable suggestions concerning asset disposal, urban renewal, and renovation. Later obsolescence of buildings can be reduced by taking into account the proposed obsolescence criteria in the construction of new buildings to avoid implementing designs that are prone to obsolescence, thereby enhancing building service life.
\end{abstract}

Keywords: building service life, building obsolescence, Fuzzy-Delphi Method (FDM), Analytical hierarchy process (AHP), mathematical model.

\section{Introduction}

The number of existing buildings is significantly larger than that of new buildings in numerous advanced countries (Caputo et al. 2013; Cheng, Ma 2015; Vringer et al. 2016). Compared to new construction, existing buildings necessitate an increased amount of renovation and restoration (Juan 2009). The cost of renovation and restoration is roughly $50 \%$ to $80 \%$ that of new construction and the time required for renovation and restoration is roughly $50 \%$ to $70 \%$ that of new construction (Highfield, Gorse 2009). In the context of sustainable development, the sustainable renovation of existing buildings is a building management issue that must be satisfied to meet future energy saving and carbon reduction trends (Ahmad, Thaheem 2016; Langston et al. 2013).

Collective housing, a housing that features spaces and facilities for joint use by all residents who also maintain their own individual households (Krantz, Linden 1994), is the primary form of metropolitan housing in many Asian regions. For example, over $70 \%$ of housing in Taipei, Taiwan, is collective housing. Moreover, buildings over 30 years old account for $50 \%$ of the overall housing in Taipei, highlighting the old housing problem in metropolitan areas and the gradual prevalence of issues such as pipeline and equipment obsolescence, inadequate facilities, and building component damage (ABRI 2015). In response to the challenges of the immense old housing market, the government and builders are actively thinking on how to develop effective renovation methods to prolong the service life of old buildings that still have value and formulate urban renewal plans to improve the environment and quality of old buildings that are no longer useful (Malmgren, Mjörnell 2015; Rauf, Crawford 2015).

Taiwan is an island nation located on the Pacific Ring of Fire, where many volcanoes and earthquakes are formed. In comparison with several European countries and the United States, the service life of buildings in Taiwan is comparatively shorter (roughly 30 to 40 years) (Ho, Chiu 2006). According to relevant construction laws and regulations, the service life of reinforced concrete (RC) buildings is at least 60 years. This indicates that building demolition in Taiwan is not purely due to physical obsolescence. Rather, the service life of buildings in 
Taiwan is influenced by a variety of factors, such as a complex economy (e.g. investment return considerations), society (e.g. cityscape considerations), function (e.g. inadequacies), technology (e.g. smart building equipment update), and laws and regulations (e.g. failure to meet fire prevention or accessibility requirements) (ABRI 2015).

Previous studies on building durability largely focused on physical obsolescence (Langston, Shen 2007; Juan et al. 2009). Few studies have focused on the complex, non-obsolescence factors because of the large scope of these factors and the immense difficulty to quantify them (Vakili-Ardebili 2007). In this context, building a systematic approach that contains a set of evaluation criteria encompassing all possible factors influencing building service life, and then using this system to assess the obsolescence conditions and predict the service life of buildings, will be extremely beneficial for the future promotion of existing buildings from sustainability to longevity.

Therefore, the objective of the present study is to propose a systematic approach to analyze and predict the reasonable service life of buildings. To achieve this objective, research is divided into three stages. In the first stage, a literature review and expert interviews are conducted to establish a framework for the evaluation criteria of building service life. The Fuzzy-Delphi Method (FDM) and analytical hierarchy process (AHP) are adopted to determine the final evaluation criteria and weights. In the second stage, the criteria and weights are used to develop a building diagnosis and obsolescence evaluation method. In the third stage, a mathematical model based on Langston and Shen's (2007) studies for predicting building service life is developed by combining the evaluation criteria, six obsolescence factors, and diagnostic scores. Finally, the model is applied to four case studies, and the results are compared to the expert evaluations.

\section{Overview of assessment criteria that influence building service life}

In recent decades, there has been a growing interest in evaluating the durability, longevity and service life of materials and components of buildings (Bordalo et al. 2011; Grant et al. 2014). According to these studies, there are three basic methods of service life prediction: deterministic, probabilistic, and engineering methods (Lacasse, Sjöström 2004). The first method is based on the study of degradation factors that can be quantitatively translated into values and functions to express the remaining service life of building components; for example, the International Organization for Standardization (ISO) 15686-1 presented "The ISO Factor Method" to estimate service life (ISO 15686-1 2000). The second method is usually based on probabilistic calculation to define the likelihood of a change of the state of components occurring with the objective of overcoming the uncertainties related to degradation; for example, Wang and Shen (2013) adopted the Markov chain model based on stochastic approach to estimate the building deterioration and service life. The engineering methods are straightforward and they are often evaluated by modeling the performance of components for a given set of degradation scenarios. In addition to above-mentioned models, there are new models based on computation and algorithm approach are developed to explore service life prediction for building components; for example, Silva et al. (2011) used artificial neural networks (ANN) to predict service life of exterior stone cladding for specific buildings; Dias et al. (2014) applied ANN to evaluate the service life of painted surfaces based on field observations on 160 buildings. Grant and Ries (2013) developed a process that incorporated service life, operational energy, and life cycle assessment (LCA) modeling to provide a means of examining the effects of materials and systems in building operation, maintenance, repair and replacement. The process advanced the field of building LCA by representing a more complete and accurate building life cycle. However, these previous studies on building durability largely focused on physical obsolescence. Other aspects including a variety of factors that may influence building service life have been less discussed.

The service life of a building may be affected by various sociological, economic and cultural factors including urban development plans and policies (Fu et al. 2013). Sarja (2005) regarded these factors as obsolescence which means the inability of the building or its parts to adapt over time to the functional, economic and cultural requirements. The usefulness of the buildings may also be compromised by their inability to accommodate changes over time (Slaughter 2001). Through the building life cycle, all the buildings experience changes, such as changes in occupants' needs, renovation or extensions, the aging and replacement of components and systems (Augenbroe, Park 2002). The process of obsolescence and depreciation through the building life cycle may eventually lead to the end of the building service life. This process is due to several factors, including physical, economic, functional, technological, legal, aesthetic, environmental, and social obsolescence (Flores-Colen, de Brito 2010).

Langston and Shen (2007) analyzed and evaluated the reuse potential of existing buildings and proposed the adaptive reuse potential (ARP) model to examine the possible factors influencing building service life. The researchers categorized these factors into various dimensions of physical obsolescence, economic obsolescence, functional obsolescence, technical obsolescence, social obsolescence, and regulatory obsolescence. In other words, this study proposed a comprehensive evaluation framework that encompassed both physical and nonphysical obsolescence factors. It is thus a suitable basis for the evaluation of reasonable building service life in the future. Misırlısoy and Günçe (2016) also presented a comprehensive review of the factors affecting adaptive reuse decision-making and to develop a holistic model for adaptive reuse strategies for heritage buildings. Five 
factors including actors, analysis of existing fabric, conservation actions, adaptive reuse potentials, and function changes were defined.

The evaluation criteria for building service life were developed mainly based on the APR model, wherein regional housing, and relevant laws and regulations in Taiwan were also taken into account. The criteria were categorized into six obsolescence dimensions (Table 1). The physical dimension focused on building structure, materials, and components. The economic dimension focused on site conditions and location. The technical dimension focused on environment factors, such as noise, heat, and water. The functional dimension focused on space use function and size. The social dimension focused on environmental afforestation, neighborhood environment, and perspective. The political dimension focused on government policies and regulations. Obsolescence in any of the aforementioned factors influences building service life. However, each factor imposes a different degree of influence (weight). In the present study, six dimensions, 27 evaluation criteria, and 94 sub-criteria are presented.

\section{Combining Fuzzy-Delphi and AHP for determin- ing assessment criteria of building service life}

\subsection{Fuzzy-Delphi Method (FDM)}

The traditional Delphi method has always suffered from low convergence expert opinions and high execution cost because this method requires multiple investigations to achieve the consistency of expert opinions (Kuo, Chen 2008). Murry et al. (1985) thus proposed an approach of integrating the traditional Delphi method and the fuzzy theory to improve the vagueness and ambiguity of the Delphi method. Hsu and Yang (2000) applied triangular fuzzy number to encompass expert opinions and establish the Fuzzy-Delphi Method (FDM). The max and min value of expert opinions are taken as the two terminal points of triangular fuzzy numbers, and the geometric mean is taken as the membership degree of triangular fuzzy numbers to derive the statistical unbiased effect and avoid the impact of extreme values. The advantage of this method is simplicity that all the expert opinions can be encompassed in one investigation. Therefore, FDM can acquire a better result of criteria selection (Ma et al. 2011). In this research, FDM was adopted in the selection of assessment criteria of building service life. Geometric means are used to denote experts' consensus, and the process is demonstrated as follows.

Experts' opinions were collected from questionnaire. The triangular fuzzy numbers $\widetilde{T}_{i}$ were also created as follows:

$$
\begin{gathered}
\widetilde{T}_{i}=\left(C_{i}, G_{i}, O_{i}\right) ; \\
C_{i}=\min \left(X_{i j}\right) ; \\
G_{i}=\sqrt[n]{\prod_{j=1}^{n} X_{i j}} ; \\
O_{i}=\max \left(X_{i j}\right),
\end{gathered}
$$

where: $i$ is the number of criteria; $j$ is the number of experts; $C_{i}$ is the bottom of all the experts' evaluation value for criterion $i$; $O_{i}$ is the ceiling of all the experts' evaluation value for criterion $i$; $G_{i}$ is the geometric mean of all the experts' evaluation value for criterion $i ; X_{i j}$ is the evaluation value of the $j$ th expert for the criterion $i$.

Selection of assessment criteria of building service life: the geometric mean $G_{i}$ of each criterion's triangular fuzzy number was used to denote the consensus of the expert group on the criterion's evaluation value. The

\begin{tabular}{|c|c|c|c|}
\hline Dimension & Criteria & Dimension & Criteria \\
\hline Physical & $\begin{array}{l}\text { Basic structure } \\
\text { Structural integrity } \\
\text { Material durability } \\
\text { Maintainability }\end{array}$ & Functional & $\begin{array}{l}\text { Spatial dimension } \\
\text { Circulation } \\
\text { Function }\end{array}$ \\
\hline Economic & $\begin{array}{l}\text { Planning conditions } \\
\text { Regional development overview }\end{array}$ & Social & $\begin{array}{l}\text { Landscape } \\
\text { Imagery } \\
\text { Cityscape } \\
\text { Aesthetic } \\
\text { History } \\
\text { Neighborhood environment }\end{array}$ \\
\hline Technical & $\begin{array}{l}\text { Noise level } \\
\text { Indoor lighting and daylight utilization } \\
\text { Opening design } \\
\text { Ventilation } \\
\text { Building Insulation and shade } \\
\text { Air conditioning system } \\
\text { Indoor drainage } \\
\text { Water-saving equipment }\end{array}$ & Political & $\begin{array}{l}\text { Smart and green buildings } \\
\text { Accessibility } \\
\text { Property management } \\
\text { Urban renewal potential }\end{array}$ \\
\hline
\end{tabular}
threshold value $k$ was determined. If $G_{i}$ is no less than $k$, criterion $i$ is accepted, and vice versa.

Table 1. Evaluation criteria of building service life 


\subsection{AHP methodology}

The analytical hierarchy process (AHP) technique is a common multi-criteria decision making method (Dweiri et al. 2016). It structures a decision problem into a hierarchy of criteria, sub-criteria, and alternatives, followed by a series of pair-wise comparisons to derive prioritized scales. This pair-wise comparison allows finding the relative weight if the criteria with respect to the main goal (Dweiri et al. 2016). AHP has been applied to a diverse array of problems with the calculation process as follows (Sharma et al. 2008).

Establishment of pair-wise comparison matrix $A$. Let $A_{1}, A_{2}, \ldots, A_{n}$ denote the set of elements, while $a_{i j}$ represents a quantified judgment on a pair of elements $A_{i}$, and $A_{j}$. The relative importance of two elements is rated using a scale with the values $1,3,5,7$, and 9, where 1 refers to "equally important", 3 denotes "slightly more important", 5 equals "strongly more important", 7 represents "demonstrably more important", and 9 denotes "absolutely more important". This yields an $n^{*} n$ matrix $A$ as follows:

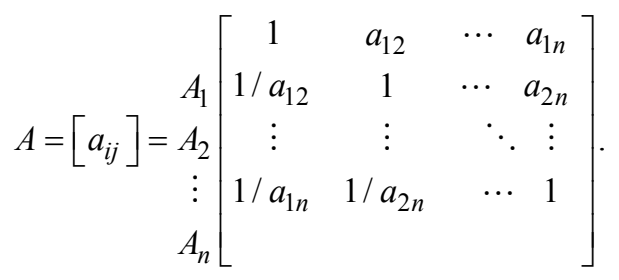

In matrix $A$, the problem becomes one of assigning to the $n$ elements $A_{1}, A_{2}, \ldots, A_{n}$ a set of numerical weights $W_{1}, W_{2}, \ldots, W_{n}$ that reflect the recorded judgment. If $A$ is a consistence matrix, the relations between weights $W_{i}$ and judgment $a_{i j}$ are simply given $W_{i} / W_{j}=a_{i j}$. This study uses AHP to define the weights of expressing the relative importance of assessment criteria and subcriteria of building service life determined by experts.

\subsection{Determination of criteria and corresponding weights}

First, the FDM was employed to screen the various criteria. According to previous studies, the suggested number of experts for a Fuzzy-Delphi questionnaire survey is between 5 and 15 (Hsu, Chen 1996). Fourteen experts, including 2 government officials in building administration, 2 architects, 3 managers in construction companies, 2 building renovation contractors, 2 real estate appraisers, and 3 researchers and professors in building management from universities were invited to participate in a questionnaire survey. The experts were proficient in building diagnosis and renovation. The Gi threshold value was set at 5.29. Criteria with a lower score than the threshold value failed to achieve expert consensus and were excluded from the present study. Therefore, 9 of the 27 criteria were excluded, and 49 of the 94 sub-criteria were excluded.

Second, a total of 18 criteria and 45 sub-criteria remained following the FDM elimination process. They were processed using the AHP to obtain the various weight values (Table 2). The criteria and sub-criteria of the physical dimension achieved the highest weight values, suggesting that this dimension significantly influenced building service life, while the criteria and sub-criteria of the social dimension achieved the lowest weight values. The more influential criteria were basic structure, structural integrity, and insulation and shade, while the less influential criteria were history and accessibility. The more influential sub-criteria were structural crack or deformation, severity of western exposure, and short-column or short-beam effect, while the less influential sub-criteria were community cleanliness, environment friendliness, and regional identity.

\section{Mathematic model for predicting building service life}

\subsection{Development of the mathematic model}

Langston and Shen (2007) proposed a mathematical model to determine the physical and useful life of buildings, with the latter being deemed to be discounted physical life, where the discount rate is taken as the sum of the obsolescence factors. In other words, the useful life will be shortened owing to various obsolescence factors. The relationship is given by Eqn (3):

$$
L_{u}=\frac{L_{p}}{\left(1+\sum_{i=1}^{n} O_{i}\right)^{L_{p}}},
$$

where: $L_{u}$ is the useful life (years); $L_{p}$ is the physical life (years); $O_{i}$ is the obsolescence rate of the $i$ factor $(\%$ as decimal p.a.).

Based on each evaluation item, the criteria tabulated in Table 2 were categorized into four levels. Criteria in Level 1 are the optimal diagnostic criteria while those in Level 4 are the criteria with the most severe obsolescence. Each criterion has corresponding evaluation semantics, and the scores are equally distributed from 0-100\%. The degree of obsolescence for a sub-criterion was calculated by multiplying the evaluation score with the absolute weight (of the sub-criterion). The sum of the degree of obsolescence values of all sub-criteria was the degree of obsolescence for the dimension (Eqn (4)). The "structural crack or deformation" sub-criterion is adopted as an example for calculations (Table 3).

$$
O_{i}=\sum_{j=1}^{m} X_{j}=\sum_{j=1}^{m} S_{j} \times W_{j}
$$

where: $O_{i}$ is the obsolescence rate of the $i$ factor $(\%$ as decimal p.a.); $X_{j}$ is the obsolescence rate of the $j$ subcriterion ( $\%$ as decimal p.a.); $S_{j}$ is the assessment score for the $j$ sub-criterion ( $\%) ; W_{j}$ is the absolute weight for the $j$ sub-criterion (\%). 
Table 2. Criteria weights for building service life

\begin{tabular}{|c|c|c|c|}
\hline $\begin{array}{l}\text { Dimension } \\
\text { (weight) }\end{array}$ & Criteria (weight) & Sub-Criteria (weight) & $\begin{array}{c}\text { Absolute } \\
\text { Weight }\end{array}$ \\
\hline \multirow[t]{12}{*}{ Physical (0.438) } & \multirow[t]{2}{*}{ Basic structure (0.204) } & Basic structure type $(0.617)$ & 0.055 \\
\hline & & Distance from seismic belt $(0.383)$ & 0.034 \\
\hline & \multirow[t]{6}{*}{ Structural integrity (0.599) } & Floor plan $(0.118)$ & 0.031 \\
\hline & & Facade $(0.112)$ & 0.029 \\
\hline & & Illegal construction on roof $(0.090)$ & 0.024 \\
\hline & & Structural crack or deformation $(0.368)$ & 0.097 \\
\hline & & Leakage $(0.100)$ & 0.026 \\
\hline & & Short-column or short-beam effect $(0.212)$ & 0.056 \\
\hline & \multirow[t]{2}{*}{ Material durability (0.111) } & Concrete spalling (0.483) & 0.023 \\
\hline & & Effect of Chloride ions $(0.517)$ & 0.025 \\
\hline & \multirow[t]{2}{*}{ Maintainability (0.086) } & Open piping design $(0.658)$ & 0.025 \\
\hline & & Independent piping closet $(0.342)$ & 0.013 \\
\hline \multirow{5}{*}{$\begin{array}{l}\text { Economic } \\
(0.099)\end{array}$} & \multirow[t]{2}{*}{ Planning conditions $(0.589)$} & Urban use zoning $(0.781)$ & 0.046 \\
\hline & & Site dimensions $(0.219)$ & 0.013 \\
\hline & \multirow[t]{3}{*}{ Regional development overview (0.411) } & Living requirement $(0.234)$ & 0.010 \\
\hline & & Availability of public transport $(0.452)$ & 0.018 \\
\hline & & Distance to park greenbelt $(0.314)$ & 0.013 \\
\hline \multirow{7}{*}{$\begin{array}{l}\text { Technical } \\
(0.229)\end{array}$} & \multirow[t]{2}{*}{ Opening design (0.284) } & Window opening rate $(0.425)$ & 0.015 \\
\hline & & Ventilation $(0.575)$ & 0.021 \\
\hline & \multirow[t]{3}{*}{ Insulation and shade $(0.157)$} & Shade design (0.359) & 0.046 \\
\hline & & Indoor temperature and humidity $(0.144)$ & 0.018 \\
\hline & & Severity of western exposure $(0.497)$ & 0.064 \\
\hline & \multirow[t]{2}{*}{ Indoor plumbing (0.559) } & Integrity of drainage equipment $(0.405)$ & 0.026 \\
\hline & & Drainage smoothness $(0.595)$ & 0.039 \\
\hline \multirow{6}{*}{$\begin{array}{l}\text { Functional } \\
(0.117)\end{array}$} & \multirow[t]{2}{*}{ Spatial dimension $(0.126)$} & Total area $(0.548)$ & 0.008 \\
\hline & & Indoor height $(0.452)$ & 0.007 \\
\hline & \multirow[t]{2}{*}{ Circulation $(0.288)$} & Indoor circulation smoothness $(0.154)$ & 0.005 \\
\hline & & Evacuation distance $(0.846)$ & 0.029 \\
\hline & \multirow[t]{2}{*}{ Function $(0.586)$} & Spatial satisfaction $(0.579)$ & 0.040 \\
\hline & & Fire prevention zoning $(0.421)$ & 0.029 \\
\hline \multirow[t]{7}{*}{ Social $(0.045)$} & \multirow[t]{2}{*}{ Cityscape (0.329) } & Façade cleanliness $(0.306)$ & 0.005 \\
\hline & & Consistency of external ornaments (0.694) & 0.010 \\
\hline & \multirow[t]{2}{*}{ History $(0.146)$} & Unnatural factor obsolescence $(0.590)$ & 0.004 \\
\hline & & Regional identity (0.410) & 0.003 \\
\hline & \multirow[t]{3}{*}{ Neighborhood environment (0.525) } & Function satisfaction $(0.263)$ & 0.006 \\
\hline & & Safety $(0.578)$ & 0.014 \\
\hline & & Quality satisfaction $(0.159)$ & 0.004 \\
\hline \multirow[t]{8}{*}{ Political (0.073) } & \multirow[t]{2}{*}{ Accessibility (0.110) } & Integrity of accessible facilities (0.688) & 0.006 \\
\hline & & Environment friendliness $(0.312)$ & 0.003 \\
\hline & \multirow[t]{4}{*}{ Property management $(0.550)$} & Public safety inspection $(0.663)$ & 0.027 \\
\hline & & Long-term restoration fund $(0.182)$ & 0.007 \\
\hline & & Safety control $(0.099)$ & 0.004 \\
\hline & & Community cleanliness $(0.056)$ & 0.002 \\
\hline & \multirow[t]{2}{*}{ Urban renewal potential $(0.340)$} & Building age $(0.425)$ & 0.011 \\
\hline & & Residents' urban renewal intention $(0.575)$ & 0.014 \\
\hline
\end{tabular}


Table 3. Calculating the degree of obsolescence for structural crack or deformation

\begin{tabular}{lc}
\hline \multicolumn{1}{c}{ Structural crack or deformation (absolute weight: $9.7 \%$ ) } & Score \\
\hline Level 1: Structure exhibits no cracks or deformation & $0 \%$ \\
Level 2: Structure exhibits cracks roughly $0.5 \mathrm{~mm}$ in width and deformation of roughly $1 \%$ to $15 \%$ & $33 \%$ \\
Level 3: Structure exhibits cracks over $0.5 \mathrm{~mm}$ in width and deformation of roughly $16 \%$ to $30 \%$ & $67 \%$ \\
Level 4: Structures exhibit significant cracking or exposed rebar and deformation of over 30\% & $100 \%$ \\
\hline Assessment result & Level 2 \\
\hline Obsolescence rate $\left(X_{j}\right)$ & $3.2 \%$ \\
\hline
\end{tabular}

\subsection{Case study}

Four collective housing buildings were adopted as the targets for case studies. The criteria of selecting these four cases were based on some characteristics of current housing market in north Taipei: (1) they are located Taipei City and New Taipei City; (2) they were between 25 and 35 years old (accounts for $68 \%$ of total existing buildings); (3) they contain 8 to 12 floors (accounts for $33 \%$ of total existing buildings); (4) the average area per unit was between 93 to $148 \mathrm{~m}^{2}$ (accounts for $45 \%$ of total existing buildings). The targets were analyzed using the aforementioned evaluation method and mathematical model. The analytical results are tabled in Table 4. Assuming that the physical service life was a minimum of
60 years in accordance with relevant construction laws and regulations, the service life of the four targets were estimated to be between 42 and 50 years, depending on the targets' degree of obsolescence. For example, the ages of Case A and Case C were over 30 years. Case C is located in a central suburban region. Although it exhibited severe economic obsolescence, its overall degree of physical, technical, functional, social, and political obsolescence was relatively weak, and thus manifested a relatively longer service life. The ages of Case B and Case D were similar. However, it was evident that Case $\mathrm{B}$ was overused and undermaintained, exhibiting more severe physical, technical, and functional obsolescence and therefore manifesting a shorter service life.

Table 4. Model demonstration of four congregate housing buildings

\begin{tabular}{|c|c|c|c|c|}
\hline & Case A & Case B & Case C & Case D \\
\hline Project & 3én & 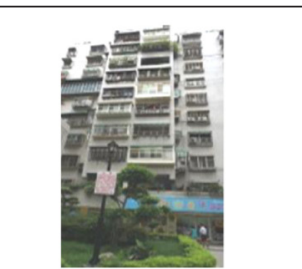 & 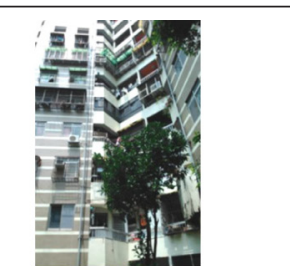 & 18 \\
\hline Debriefing & $\begin{array}{l}\text { Current building age: } \\
35 \text { years } \\
12 \text { floors (RC } \\
\text { structure) } \\
43 \text { units } \\
\text { average area per unit: } \\
113 \mathrm{~m}^{2}\end{array}$ & $\begin{array}{l}\text { Current building age: } \\
28 \text { years } \\
10 \text { floors (RC } \\
\text { structure) } \\
40 \text { units } \\
\text { average area per unit: } \\
140 \mathrm{~m}^{2}\end{array}$ & $\begin{array}{l}\text { Current building age: } \\
30 \text { years } \\
12 \text { floors (RC } \\
\text { structure) } \\
192 \text { units } \\
\text { average area per unit: } \\
90 \mathrm{~m}^{2}\end{array}$ & $\begin{array}{l}\text { Current building } \\
\text { age: } 26 y e a r s \\
11 \text { floors (RC } \\
\text { structure) } \\
22 \text { units } \\
\text { average area per } \\
\text { unit: } 84 \mathrm{~m}^{2}\end{array}$ \\
\hline \multicolumn{5}{|l|}{ Obsolescence coefficient } \\
\hline Physical & $11.06 \%$ & $9.54 \%$ & $6.35 \%$ & $5.49 \%$ \\
\hline Economic & $1.18 \%$ & $4.08 \%$ & $4.65 \%$ & $3.70 \%$ \\
\hline Technical & $5.47 \%$ & $7.66 \%$ & $3.50 \%$ & $2.71 \%$ \\
\hline Functional & $3.69 \%$ & $5.69 \%$ & $1.75 \%$ & $3.82 \%$ \\
\hline Social & $1.42 \%$ & $2.60 \%$ & $1.12 \%$ & $0.66 \%$ \\
\hline Political & $4.25 \%$ & $4.32 \%$ & $1.96 \%$ & $1.72 \%$ \\
\hline \multicolumn{5}{|l|}{ Building service life information } \\
\hline Physical life & 60 years & 60 years & 60 years & 60 years \\
\hline Predicted service life & 45.7 years & 42.8 years & 49.5 years & 50.1 years \\
\hline Remaining service life & 10.7 years & 14.8 years & 19.5 years & 24.1 years \\
\hline Experts'predicted service life & 50.4 years & 45.6 years & 52.3 years & years \\
\hline
\end{tabular}


Table 5. Fuzzy number of predicted service life from experts for Case A

\begin{tabular}{cccc}
\hline Experts & $\begin{array}{c}\text { Fuzzy number } \\
(L E, M E, U E)\end{array}$ & $\begin{array}{c}\text { Defuzzi- } \\
\text { fication }\end{array}$ & $\begin{array}{c}\text { Average experts' } \\
\text { predicted service life } \\
\text { (years) }\end{array}$ \\
\hline E1 & $(35,48,50)$ & 45.3 & \\
E2 & $(40,48,60)$ & 49.0 & \\
E3 & $(45,50,55)$ & 50.0 & 50.4 \\
E4 & $(50,52,56)$ & 52.5 & \\
E5 & $(46,52,56)$ & 51.5 & \\
E6 & $(48,54,60)$ & 54.0 & \\
\hline
\end{tabular}

Note: The fuzzy numbers are distributed from 1 to 60 years.

Six experts were invited to form a diagnostics team. The experts were specialists in the fields of building service engineering, structural engineering, and architectural engineering. They physically visited each case to perform a field survey and make service life predictions. Their predictions were generally based on their experiences and empirical data with focus on structural engineering problems, such as the structural integrity and fatigue of materials in accord with physical loading, ongoing chemical reactions, and degradation over time. However, this approach also has certain limitation; some factors other than physical degradation might be excluded from the service life prediction (Grant et al. 2014). Since different experts have significant discrepancies in judgment on service life predictions, a questionnaire based on a fuzzy sets theory was used and a fuzzy number () was built to help characterize the uncertainty. The linguistic variables were determined and then translated into fuzzy numbers by defining appropriate membership functions. In this study, for example, let $\mathrm{F}=\{\mathrm{VS}, \mathrm{S}, \mathrm{M}, \mathrm{L}, \mathrm{VL}\}$ be a linguistic set used to express opinions on predicted service life for the building (VS: very short; S: short; M: medium; L: long; VL: very long). Figure 1 was a sample of one expert revealing the fuzzy number of $\mathrm{F}=\{(0,0,20),(10,20$,

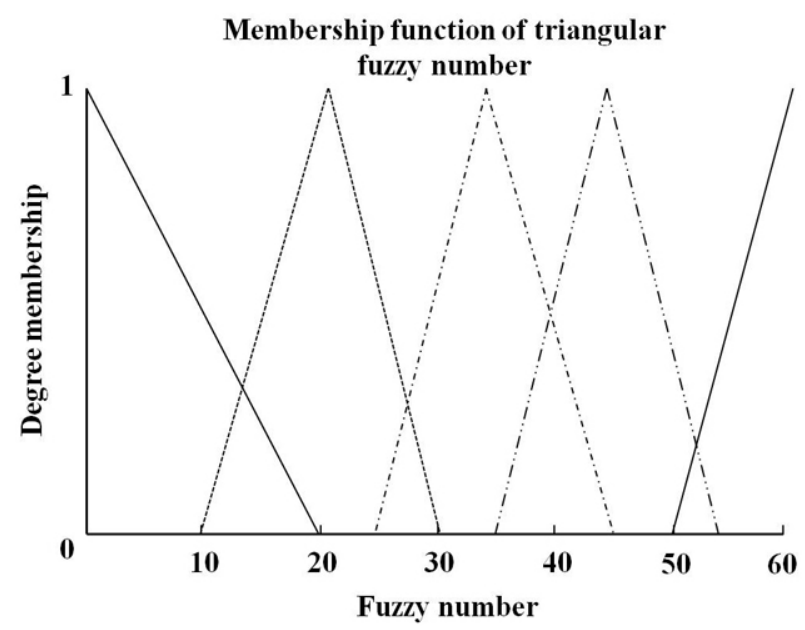

Fig. 1. Sample of fuzzy number for service life prediction
$30),(25,35,45),(35,45,55),(50,60,60)\}$. The average fuzzy number was computed by the following equation, and the result was shown in Table 5.

$$
\left(\tilde{E}_{i}\right)=\frac{1}{k} \times\left(L E_{i}^{k}, M E_{i}^{k}, U E_{i}^{k}\right),
$$

where $\tilde{E}_{i}$ is the average fuzzy number of the service life prediction determined by $k$ experts; $L E_{i}^{k}, M E_{i}^{k}$, and $U E_{i}^{k}$ denote lower, medium, and upper values of the service life, respectively.

The fuzzy set that describes a linguistic value sometimes has to be expressed by a crisp value to illustrate the service life prediction of quantitative criteria, which means defuzzification (Bojadziev, G., Bojadziev, M. 1997). The defuzzification method, based on the Facchinetti et al. (1998) approach, is denoted as Eqn (6):

$$
N F_{i}=\left(L E_{i}+2 M E_{i}+U E_{i}\right) / 4 .
$$

Expert prediction outcomes indicated an increased emphasis on physical, technical, and functional obsolescence with less consideration in the other dimensions, leading to slightly elevated prediction values compared to the values produced by the proposed prediction model. However, the margin of error between the two sets of results was acceptable (mean margin of error is roughly $5.5 \%$ ), verifying that the proposed model is not only reliable but also time efficient. Therefore, the model is suitable for future large-scale application and promotion.

\section{Conclusion and suggestions}

The number of existing buildings is immense. Collective housing is the primary form of metropolitan housing in many Asian regions. Aging buildings not only affect living quality but also impact cityscapes negatively. Adopting appropriate processes to understand the reasonable service life of buildings is the first step in creating sustainable built environments. If buildings manifest service value, sustainable refurbishment and reuse methods can be employed to extend their service life; otherwise, urban renewal or asset disposal plans should be implemented as soon as possible.

The present study transcends the conventional evaluation of buildings that largely focus on physical obsolescence by taking into account economic, technical, social, functional, and political obsolescence factors. These factors were collated to establish a robust set of evaluation criteria and obsolescence factors specific to building service life, which were rarely explored in prior studies. A mathematical model for predicting building service life was developed by systematically combining the evaluation criteria, six obsolescence factors, and diagnostic scores. The results produced by the model were consistent with those determined by an expert panel, verifying the reliability of the proposed model. The proposed model can save the time and resources required to conduct onsite diagnostics and evaluations, rendering it extremely 
beneficial and effective means for comprehensively reviewing old housing problems in the future.

Although the present study is centered on the diagnosis and evaluation of old buildings, the obsolescence criteria obtained in this study can be converted into design principles and precautions for the construction of new buildings. In other words, the later obsolescence of buildings can be reduced by taking into account the proposed obsolescence criteria in the construction of new buildings to avoid implementing designs that are prone to obsolescence, thereby achieving the promotion of buildings from sustainability to longevity. This assumption is similar to the concept of performance-based building that design buildings to meet or exceed identified projectspecific targets and performance requirements, which can effectively prolong the service life for buildings (Trinius, Sjöström 2005).

This study presents some limitations of the research, and provides the suggestions for the future studies. First, the initially proposed model was merely verified using four case buildings. In the future, the model can be applied to a variety of building types to test and revise its performance, thereby improving its applicability. Next, although the criteria established in this present study are more suitable for the buildings in Taiwan, they could be adjusted if intended to be applied to other regions, cities, or countries. Moreover, developing a decision support system that can easily conduct the building service life prediction and offers optimal refurbishment solutions to extend the service life within limited budget is essential for occupants. Due to the rapid improvement of technology, potential BIM functionalities and benefits in extending service life in existing buildings are promising; a BIM-based monitoring of building components combining onsite progress tracking and measurements through cloud computing depict potential future trends of automated capture and transformation of building information in maintenance, retrofit or remediation processes into BIM.

\section{Acknowledgements}

This study was funded by the Architecture and Building Research Institute, Ministry of the Interior, Taiwan (R.O.C.), as Project No. PG10401-0558.

\section{References}

Ahmad, T.; Thaheem, M. J. 2016. Developing a residential building-related social sustainability assessment framework and its implications for BIM, Sustainable Cities and Society 26: 1-15. https://doi.org/10.1016/j.scs.2016.08.002

Architecture and Building Research Institute (ABRI). 2015. Investigating and developing improvement strategies for building obsolescence of multi-unit residential buildings. ABRI, Ministry of the Interior, Taiwan.

Augenbroe, G.; Park, C. S. 2002. Towards a maintenance performance toolkit for GSA. Draft Report for distribution in GSA, USA.

Bojadziev, G.; Bojadziev, M. 1997. Fuzzy logic for business, finance, and management. Singapore: World Scientific. https://doi.org/10.1142/3312
Bordalo, R.; de Brito, J.; Gaspar, P.L.; Silva, A. 2011. Service life prediction modeling of adhesive ceramic tiling systems, Building Research \& Information 39(1): 66-78. https://doi.org/10.1080/09613218.2010.532197

Caputo, P.; Costa, G.; Ferrari, S. 2013. A supporting method for defining energy strategies in the building sector at urban scale, Energy Policy 55: 261-270.

https://doi.org/10.1016/j.enpol.2012.12.006

Cheng, J. C. P; Ma, L. J. 2015. A data-driven study of important climate factors on the achievement of LEED-EB credits, Building and Environment 90: 232-244. https://doi.org/10.1016/j.buildenv.2014.11.029

Dias, J. L.; Silva, A.; Chai, C.; Gaspar, P.L.; de Brito, J. 2014. Neural networks applied to service life prediction of exterior painted surfaces, Building Research \& Information, 42 (3), 371-380. https://doi.org/10.1080/09613218.2013.819551

Dweiri, F.; Kumar, S.; Khan, S. A.; Jain, V. 2016. Designing an integrated AHP based decision support system for supplier selection in automotive industry, Expert Systems with Applications 62: 273-283. https://doi.org/10.1016/j.eswa.2016.06.030

Facchinetti, G.; Ricci, R. G.; Muzzioli, S. 1998. Note on ranking fuzzy triangular numbers, International Journal of Intelligent Systems 13: 613-622.

https://doi.org/10.1002/(SICI)1098-

111X(199807)13:7<613::AID-INT2>3.0.CO;2-N

Flores-Colen, I.; de Brito, J. 2010. A systematic approach for maintenance budgeting of buildings façades based on predictive and preventive strategies, Construction and Building Materials 24(9): 1718-1729. https://doi.org/10.1016/j.conbuildmat.2010.02.017

Fu, F.; Pan L.; Ma, L.; Li, Z. 2013. A simplified method to estimate the energy-saving potentials of frequent construction and demolition process in China, Energy 49: 316-332. https://doi.org/10.1016/j.energy.2012.10.021

Grant, A.; Ries, R. 2013. Impact of building service life models on life cycle assessment, Building Research \& Information 41(2): 168-186. https://doi.org/10.1080/09613218.2012.730735

Grant, A.; Ries, R.; Kibert, C. 2014. Life cycle assessment and service life prediction-A case study of building envelope materials, Journal of Industrial Ecology 18(2): 187-200. https://doi.org/10.1111/jiec.12089

Highfield, D.; Gorse, C. 2009. Refurbishment and upgrading of buildings. London: Taylor \& Francis.

Ho, M. C.; Chiu, C. Y. 2006. Introduction to green building policy in Taiwan, in CIB W062 32nd International Symposium on Water Supply and Drainage for Buildings, 2006, Taipei, Taiwan.

Hsu, H. M.; Chen, C. T. 1996. Aggregation of fuzzy opinions under group decision making, Fuzzy Sets and Systems 79(3): 279-285. https://doi.org/10.1016/0165-0114(95)00185-9

Hsu, T. H.; Yang, T. H. 2000. Application of fuzzy analytic hierarchy process in the selection of advertising media, Journal of Management \& System 7: 19-39.

ISO 15686-1. 2000. Buildings and constructed assets- Service life planning- Part 1: General principles. Geneva: International Standards Organisation.

Juan, Y. K. 2009. A hybrid approach using data envelopment analysis and case-based reasoning for housing refurbishment contractors selection and performance improvement, Expert Systems with Applications 36: 5702-5710. https://doi.org/10.1016/j.eswa.2008.06.053

Juan, Y. K.; Kim, J. H.; Roper, K. O.; Castro, D. 2009. GA-based decision support system for housing condition assessment and refurbishment strategies, Automation in Construction 18(4): 394-401. https://doi.org/10.1016/j.autcon.2008.10.006 
Krantz, B.; Linden, K. P. 1994. Forms of collective housing, forms of living alternatives, in $8^{\text {th }}$ World Congress of Sociology, 1994, Bielefeld, Germany.

Kuo, Y. F.; Chen, P. C. 2008. Constructing performance appraisal indicators for mobility of the service industries using Fuzzy Delphi Method, Expert Systems with Applications 35(4): 1930-1939. https://doi.org/10.1016/j.eswa.2007.08.068

Lacasse, M. A.; Sjöström, C. 2004. Recent advances in methods for service life prediction of buildings materials and components - an overview, in Proceedings of CIB World Building Congress, 2-7 May 2004, Toronto, ON, Canada.

Langston, C.; Shen, L. Y. 2007. Application of the adaptive reuse potential model in Hong Kong: A case study of Lui Seng Chun, International Journal of Strategic Property Management 11(4): 193-207.

Langston, C.; Yung, E. H. K.; Chan, E. H. W. 2013. The application of ARP modelling to adaptive reuse projects in Hong Kong, Habitat International 40: 233-243. https://doi.org/10.1016/j.habitatint.2013.05.002

Ma, Z.; Shao, C.; Ma, S.; Ye, Z. 2011. Constructing road safety performance indicators using Fuzzy Delphi Method and Grey Delphi Method, Expert Systems with Applications 38(3): 1509-1514. https://doi.org/10.1016/j.eswa.2010.07.062

Malmgren, L.; Mjörnell, K. 2015. Application of a decision support tool in three renovation projects, Sustainability 7(9): 12521-12538. https://doi.org/10.3390/su70912521

Misırlısoy, D.; Günçe, K. 2016. Adaptive reuse strategies for heritage buildings: A holistic approach, Sustainable Cities and Society 26: 91-98. https://doi.org/10.1016/j.scs.2016.05.017

Murry, T. J.; Pipino, L. L.; van Gigch, J. P. 1985. A pilot study of fuzzy set modification of Delphi, Human Systems Management 5(1): 76-80.
Rauf, A. R.; Crawford, R. H. 2015. Building service life and its effect on the life cycle embodied energy of buildings, Energy 79(1): 140-148. https://doi.org/10.1016/j.energy.2014.10.093

Sarja, A. 2005. Generic limit state design of structures, in 10th DBMC International Conference on Durability of Building Materials and Components, 2005, Lyon, France.

Sharma, M. J.; Moon, I.; Bae, H. 2008. Analytic hierarchy process to assess and optimize distribution network, Applied Mathematics and Computation 202(1): 256-265. https://doi.org/10.1016/j.amc.2008.02.008

Silva, A.; Dias, J. L.; Gaspar, P. L.; de Brito, J. 2011. Service life prediction models for exterior stone cladding, Building Research \& Information 39(6): 637-653. https://doi.org/10.1080/09613218.2011.617095

Slaughter, E. S. 2001. Design strategies to increase building flexibility, Building Research \& Information 29(3): 208217. https://doi.org/10.1080/09613210010027693

Trinius, W.; Sjöström, C. 2005. Service life planning and performance requirements, Building Research \& Information 33(2): 173-181. https://doi.org/10.1080/0961321042000323806

Vakili-Ardebili, A. 2007. Complexity of value creation in sustainable building design (SBD), Journal of Green Building 2(4): 171-181. https://doi.org/10.3992/jgb.2.4.171

Vringer, K.; van Middelkoop, M.; Hoogervorst, N. 2016. Saving energy is not easy: An impact assessment of Dutch policy to reduce the energy requirements of buildings, Energy Policy 93: 23-32. https://doi.org/10.1016/j.enpol.2016.02.047

Wang, E.; Shen, Z. 2013. Lifecycle energy consumption prediction of residential buildings by incorporating longitudinal uncertainties, Journal of Civil Engineering and Management 19(Supplement 1): S161-S171. https://doi.org/10.3846/13923730.2013.802744 
Appendix - Raw data for Case A

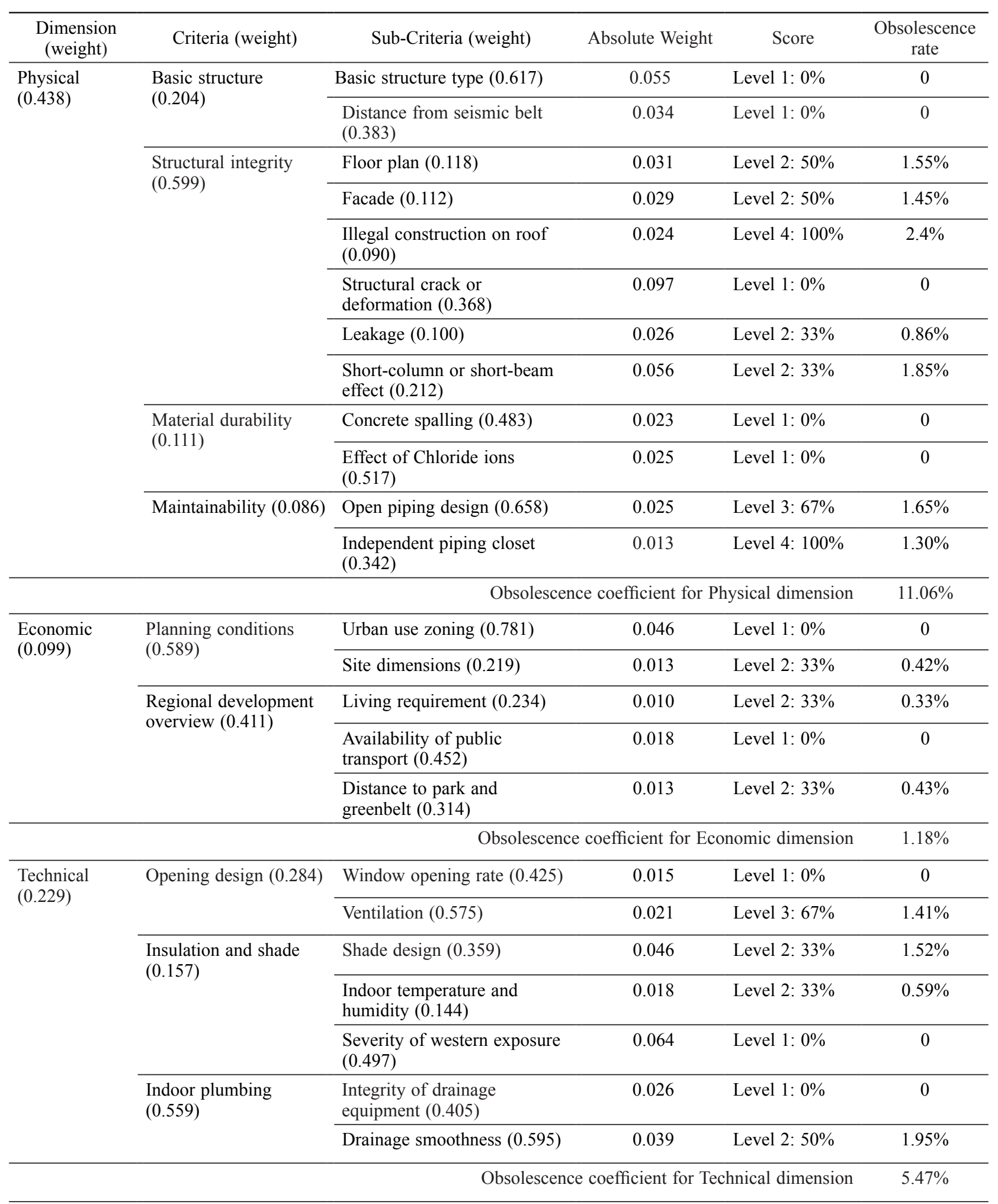


Continued Appendix

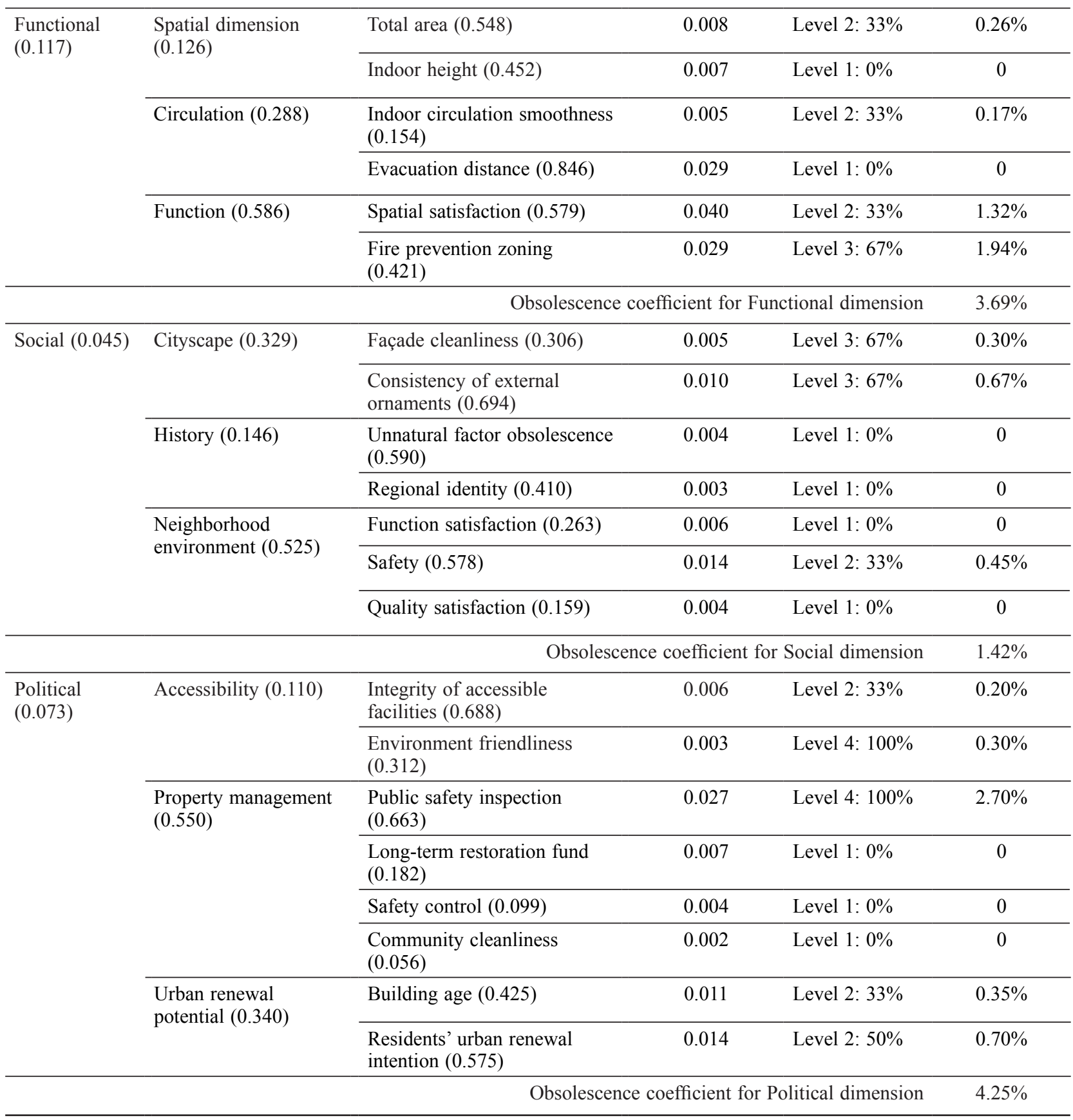




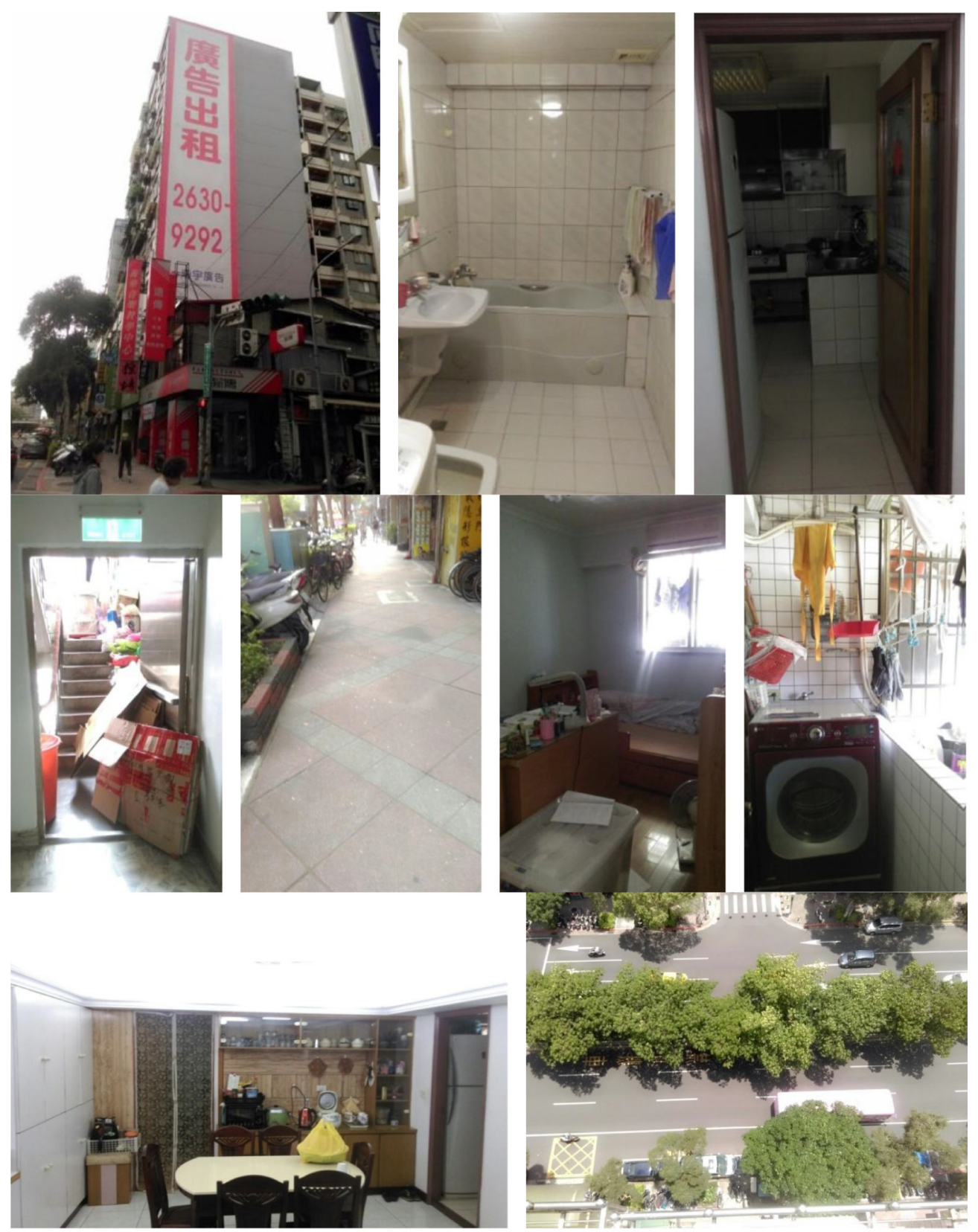

Chien-Jung Chen. PhD, Leader at Engineering Technology Group, Architecture and Building Research Institute, Ministry of the Interior. Recent research interests include BIM applied on construction technology, and innovative construction and refurbishment methods.

Yi-Kai JUAN. PhD, Associate Professor at Department of Architecture, National Taiwan University of Science and Technology (NTUST), Taipei, Taiwan. Recent research interests include sustainable development, strategic property and facility management, industry analysis, and decision support system in $\mathrm{A} / \mathrm{E} / \mathrm{C}$ industries.

Yin-Hao HSU. PhD, Researcher at Department of Architecture, National Taiwan University of Science and Technology (NTUST), Taipei, Taiwan. Recent research interests include sustainable urban development, strategic property and facility management, and urban renewal strategies. 